\title{
A differential release of matrix metalloproteinases 9 and 2 during coronary artery bypass grafting and off-pump coronary artery bypass surgery
}

Adam Sokal, PhD, ${ }^{\mathrm{a}}$ Michal Zembala, MD, ${ }^{\mathrm{b}}$ Anna Radomski, MD, ${ }^{\mathrm{c}}$ Alfred Kocher, PhD, ${ }^{\mathrm{d}}$ Jerzy Pacholewicz, PhD, Joanna Los, MD, ${ }^{\mathrm{b}}$ Ewa Jedrzejczyk, MD, ${ }^{\mathrm{a}}$ Marian Zembala, $\mathrm{PhD},{ }^{\mathrm{b}}$ and Marek Radomski, $\mathrm{PhD}^{\mathrm{c}}$

Objectives: Extracorporeal circulation is associated with the systemic inflammatory response syndrome. The objective of this study was to measure plasma and myocardial matrix metalloproteinase 2 and 9 levels in patients undergoing off-pump coronary artery bypass and coronary artery bypass grafting.

\begin{abstract}
Methods: Twenty patients subjected to coronary artery bypass grafting and 20 subjected to off-pump coronary artery bypass surgery were included in this study. In both procedures blood was collected in 7 equivalent time points up to 12 hours after grafting. The myocardial biopsy specimens were collected before and after extracorporeal circulation in the coronary artery bypass grafting group and after harvesting and completion of proximal anastomoses in the off-pump coronary artery bypass group. Matrix metalloproteinase levels were measured by means of zymography. Myeloperoxidase and tissue inhibitor of metalloproteinase 1 and 2 levels were measured with an enzyme-linked immunosorbent assay.
\end{abstract}

Results: Coronary artery bypass grafting but not off-pump coronary artery bypass led to a 700- to 900-fold increase of plasma matrix metalloproteinase 9 levels. A small but significant increase in matrix metalloproteinase 2 levels was detected in both procedures. Myocardial matrix metalloproteinase 9 levels significantly increased at the end of coronary artery bypass grafting and off-pump coronary artery bypass. Increased matrix metalloproteinase 9 activity at the end of extracorporeal circulation was accompanied by augmentation of the endogenous matrix metalloproteinase inhibitors tissue inhibitor of metalloproteinase 1 and 2 in plasma, but its magnitude was unable to balance the plasma matrix metalloproteinase 9 increase. The matrix metalloproteinase 9 content in plasma at the end of extracorporeal circulation correlated with the myeloperoxidase plasma concentration $\left(r^{2}=0.8212, P<0.05\right)$.

Conclusion: We propose that release of matrix metalloproteinase 9 might contribute to the extracorporeal circulation-induced inflammatory reactions.

Surgical coronary revascularization improves survival and quality of life and attenuates a number of cardiac-related hospitalizations in patients with coronary artery disease. ${ }^{1}$ However, extracorporeal circulation (ECC) used during coronary artery bypass grafting $(\mathrm{CABG})$ alters the structural and functional properties of circulating cells, including blood platelets and leukocytes, thus initiating their activation and promoting the generalized systemic inflammation response syndrome (SIRS). ${ }^{2,3}$ SIRS might cause severe postoperative complications, such as neurologic, renal, and pulmonary dysfunction, compromising the clinical outcome of coronary revascularization. Moreover, reperfusion after

\footnotetext{
From the 1st Department of Cardiology ${ }^{\mathrm{a}}$ and the Department of Cardiac Surgery and Transplantology, ${ }^{\mathrm{b}}$ Silesian Center for Heart Diseases, Zabrze, Poland; the School of Pharmacy and Pharmaceutical Sciences, ${ }^{\mathrm{c}}$ Trinity College, Dublin, Ireland; and the Department of Cardiac Surgery, ${ }^{\mathrm{d}}$ Medical University of Innsbruck, Innsbruck, Austria. Supported by the Polish Ministry of Science and Higher Education (2P05B13029).

Received for publication March 31, 2008; revisions received Oct 12, 2008; accepted for publication Nov 2, 2008.

Address for reprints: Adam Sokal, PhD, 1st Department of Cardiology, Silesian Center of Heart Diseases, Ul Szpitalna 2, 41-800 Zabrze, Poland (E-mail: asokal20@ yahoo.com).

J Thorac Cardiovasc Surg 2009;137:1218-24

$0022-5223 / \$ 36.00$

Copyright (c) 2009 by The American Association for Thoracic Surgery doi:10.1016/j.jtcvs.2008.11.004
}

cardioplegic arrest is associated with ischemia-reperfusion injury, and this might contribute to myocardial stunning. Off-pump coronary artery bypass (OPCAB) has been introduced as an alternative to conventional ECC-supported myocardial revascularization. The absence of ECC is thought to markedly reduce proinflammatory cytokine release, thus limiting the incidence of SIRS and SIRS-related postoperative complications. ${ }^{4}$

Matrix metalloproteinases (MMPs) are a family of zincand calcium-dependent endopeptidases responsible for the metabolism of extracellular matrix of the connective tissue. ${ }^{5}$ These proteinases play an important role in physiologic (eg, growth and development) and pathologic (eg, inflammation and cancer) processes. Of special interest for myocardial function are MMP-2 and MMP-9, which have been identified in cardiomyocytes. ${ }^{6}$ MMP-2 and MMP-9 are overexpressed in ventricular remodeling, aortic aneurysm formation, and atherosclerosis plague rupture and might contribute to the pathogenesis of these pathologies. ${ }^{7,8}$ The expression and release of MMPs is induced by proinflammatory cytokines, including tumor necrosis factor $\alpha^{9}$ and interleukin (IL) 1, IL-6, IL-8, and IL-10. ${ }^{10}$ Interestingly, MMPs augment and modulate the inflammatory response through effects on cytokine release and leukocyte extravasation. 

Abbreviations and Acronyms
$\mathrm{CABG}=$ coronary artery bypass grafting
$\mathrm{ECC}=$ extracorporeal circulation
IL = interleukin
$\mathrm{LVEF}=$ left ventricular ejection fraction
$\mathrm{MMP}=$ matrix metalloproteinase
$\mathrm{OPCAB}=$ off-pump coronary artery bypass
SIRS = systemic inflammation response syndrome
TIMP = tissue inhibitor of metalloproteinase

The changes in MMP-2 and MMP-9 levels in plasma and tissues have already been documented in patients undergoing CABG. ${ }^{11,12}$ However, to our knowledge, the release of these proteinases in patients undergoing OPCAB has not been described. Therefore we have studied the time course of plasma and myocardial levels of MMP-2 and MMP-9 in patients undergoing $\mathrm{CABG}$ and $\mathrm{OPCAB}$.

\section{MATERIALS AND METHODS \\ Patient Selection and Description}

Patients ( $\mathrm{n}=40,29$ men and 11 women) with an average age of $62 \pm$ 9.61 years undergoing elective coronary artery revascularization were enrolled in the study. Patients were enrolled after obtaining informed consent. This protocol was reviewed and approved by the Institutional Review Board of the Silesian Medical University in Katowice, Poland.

Patients with recent ( $<30$ days) myocardial infarction, very low left ventricular ejection fraction (LVEF; $<30 \%$ ), concomitant valvular or aortic disease, chronic or recent steroid therapy, chronic renal failure, malignancies, autoimmunologic disease, ongoing or recent ( $<30$ days) infection, and leukocytosis $\left(>10 \times 10^{9} / \mathrm{L}\right)$ were excluded from the study. We have also excluded patients with preoperative platelet dysfunction, as determined by means of aggregometry.

Patients with multivessel coronary disease and a left ventricular ejection of greater than $30 \%$ were included if they were deemed equally treatable with CABG and OPCAB technique by means of consensus of cardiac surgeon base of coronary angiographic analysis. The allocation of patients between 2 groups (group 1, CABG; group 2, OPCAB) was based on the institutional policy of the Silesian Centre for Heart Diseases. The policy requires surgeons to perform the off-pump procedure in all cases of appropriate coronary anatomy. The final decision regarding surgical technique (ie, $\mathrm{CABG}$ or $\mathrm{OPCAB}$ ) has been made after intraoperative evaluation of the coronary bed. For example, in case of an intramuscular course of the vessel, the CABG technique was preferable. Operating surgeons were experienced in both $\mathrm{CABG}$ and $\mathrm{OPCAB}$ procedures, as evidenced by a track record of more than 100 operations for each procedure.

\section{Sample Collection}

Samples of blood were drawn from the radial arterial monitoring line in standardized time points. In the $\mathrm{CABG}$ group these were as follows: $\mathrm{A}$, before induction of anesthesia (baseline); B, before initiation of ECC; C, immediately after aortic crossclamp removal; D, immediately after cessation of ECC; E, at 30 minutes; F, at 6 hours; and $\mathrm{G}$, at 12 hours after separation from ECC.

Time points in the OPCAB group were selected to correspond to those of CABG as follows: A, before induction of anesthesia (baseline); B, after left internal thoracic artery harvest; $\mathrm{C}$, after completion of all distal anastomoses; D, after completion of all proximal anastomoses; E, at 30 minutes; F, at 6 hours; and G, at 12 hours after completion of all anastomoses. All samples were placed in ethylenediamine tetraacetic acid tubes and centrifuged (2000g for 15 minutes at room temperature), and plasma was stored at $-70^{\circ} \mathrm{C}$ until assayed for the presence of MMP-2 and MMP-9.

Right auricular biopsy specimens were obtained in all patients at selected time points. In the CABG group these were (1) just before ECC initiation and (2) immediately after cessation of ECC. In the OPCAB group these were (1) before graft implantation and (2) after completion of all graft implantations. Biopsy samples were immediately frozen and stored at $-70^{\circ} \mathrm{C}$ until assayed for MMP-2 and MMP-9.

Mean duration of both CABG and OPCAB procedures, as well as biopsy times, are shown in Table 1.

\section{Sample Preparation and Analysis}

Frozen tissue samples were crushed with a pestle and mortar at $-70^{\circ} \mathrm{C}$ and subsequently sonicated on ice in homogenization buffer. The samples were then centrifuged at $2000 \mathrm{~g}$ for 10 minutes at $4^{\circ} \mathrm{C}$, and the resultant supernatant was used for the measurement of MMPs. Plasma samples were subjected to zymographic analysis directly after thawing.

MMP-2 and MMP-9 levels were measured by means of gelatin zymography under nonreducing conditions, as described before. ${ }^{13,14}$ Briefly, samples (20 $\mu \mathrm{g}$ of protein each) were subjected to $8 \%$ sodium dodecylsulfate-polyacrylamide gel electrophoresis with copolymerized $2 \mathrm{mg} / \mathrm{mL}$ gelatin as a substrate. After electrophoresis, gels were renaturated and stained with Coomassie Brilliant Blue. Both MMP-9 and MMP-2 were identified by means of gelatinolysis, their molecular weight in comparison with cellular (HT-1080 fibrosarcoma conditioned medium, ST1) and recombinant (ST2) MMP standards (Figure 1, $C$ and D), and inhibition with selective MMP inhibitors. The abundance of MMPs in plasma and myocardium was measured with the Gel Doc XR System (Bio-Rad Laboratories, Hercules, Calif) from calibration curves with regression analyses that were constructed by using recombinant standards. ${ }^{15}$ Plasma MMP-2 and MMP-9 were expressed in nanograms per milliliter, whereas myocardial MMPs were expressed in nanograms per milligram of protein.

The immunoreactivity of tissue inhibitor of metalloproteinase (TIMP) 1 , TIMP-2, and myeloperoxidase (MPO; a specific granulocyte activity marker) were measured in plasma by using a commercially available enzyme-linked immunosorbent assay (R\&D systems, Minneapolis, Minn), according to the manufacturer's instructions.

\section{Statistics}

Results were expressed as the mean \pm standard deviation for 20 separate measurements. Comparisons were made with the Student's $t$ test for parametric data and the Mann-Whitney test for nonparametric data.

\section{RESULTS}

Table 2 shows some clinical characteristics of patients undergoing $\mathrm{CABG}$ and $\mathrm{OPCAB}$. There were no significant differences in demographics and comorbidities in patients enrolled in both the OPCAB and CABG groups. Clinical and laboratory parameters, such as LVEF, New York Heat Association class, Canadian Cardiovascular Society grade, and red blood cell and platelet counts did not differ between the investigated groups of patients. Of note, the mean white blood cell count was higher in the OPCAB group than in the CABG group $\left(7.27 \times 10^{3} / \mu \mathrm{L}\right.$ vs $\left.6.47 \times 10^{3} / \mu \mathrm{L}, P<.05\right)$.

It is noteworthy that mortality/morbidity risk calculated according to EuroSCORE classification was similar in the CABG and OPCAB groups (2.85 vs $3.85, P=.11$ ). However, OPCAB resulted in less complete revascularization, 
TABLE 1. Mean duration of surgical intervention and time lapse to biopsy and blood sample collection (in minutes)

\begin{tabular}{lcccccccccc}
\hline & & & \multicolumn{8}{c}{ Blood samples: Time points } \\
\cline { 3 - 10 } & $\begin{array}{c}\text { Operation } \\
\text { time }\end{array}$ & $\begin{array}{c}\text { Biopsy } \\
\text { specimen no. 1 }\end{array}$ & $\begin{array}{c}\text { Biopsy } \\
\text { specimen no. 2 }\end{array}$ & $\mathbf{A}$ & $\mathbf{B}$ & $\mathbf{C}$ & D & E & F & G \\
\hline CABG & $241 \pm 74.8$ & $87.2 \pm 45.8$ & $181 \pm 72.7$ & 0 & $76.6 \pm 33.5$ & $156 \pm 43.3$ & $193 \pm 63.3$ & $224 \pm 48.1$ & $557 \pm 135$ & $911 \pm 344$ \\
OPCAB & $180 \pm 40.3$ & $65.3 \pm 21.6$ & $138 \pm 33.9$ & 0 & $57 \pm 13.9$ & $120 \pm 33.4$ & $135 \pm 38.7$ & $165 \pm 40.7$ & $488 \pm 119$ & $848 \pm 195$ \\
$P$ value & .003 & .03 & .0027 & & .02 & .005 & .0002 & .0002 & .0001 & .0004 \\
\hline
\end{tabular}

$C A B G$, Coronary artery bypass grafting; $O P C A B$, off-pump coronary artery bypass.

with a smaller number of coronary anastomoses (2.1 vs $2.75, P=.01)$.

\section{Time Course of Plasma and Myocardial MMP-9}

Plasma MMP-9 concentrations measured at the beginning of surgical intervention (baseline, time point $\mathrm{A}$ ) were similar in both groups. At time point $\mathrm{C}$, a significant increase in plasma MMP-9 levels was only noted in the CABG group. At time point D, MMP-9 concentrations in this group of patients were increased by 700 - to 900 -fold. In contrast, in the OPCAB group MMP-9 concentrations in plasma remained unaltered throughout the operation. However, a slight increase was observed 6 hours after the completion of coronary anastomoses (Figure 1, A).
The myocardial MMP-9 level was significantly increased at the end of surgical revascularization in both groups (Figure $2, A)$. No significant differences were found between the 2 groups.

\section{Time Course of Plasma and Myocardial MMP-2}

The concentrations of MMP-2 in the plasma of both the $\mathrm{CABG}$ and $\mathrm{OPCAB}$ groups were unaltered during the operation. However, a small but significant increase in plasma MMP-2 levels in both groups was detected 12 hours after the operation (Figure 1,B).

The myocardial MMP-2 level in myocardium in both groups was significantly increased after surgical intervention (Figure 2, B).
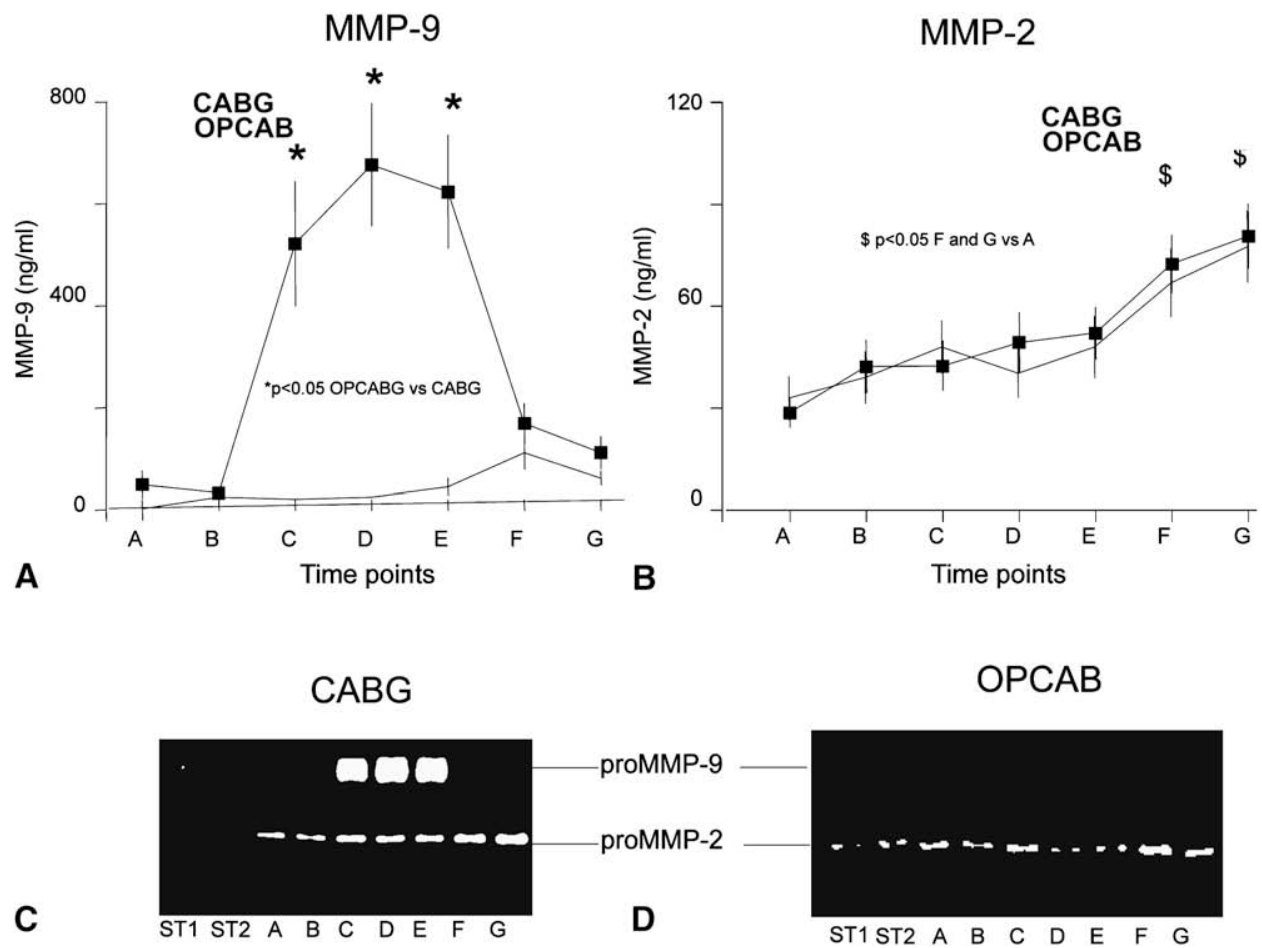

FIGURE 1. Top, Plasma gelatinase concentrations during coronary artery bypass grafting $(C A B G ; \mathrm{A})$ and off-pump coronary artery bypass $(O P C A B$; B) determined by means of quantitative zymographic analysis (see the Materials and Methods section). CABG resulted in great release of matrix metalloproteinase (MMP) 9, an effect not detected during OPCAB. Both CABG and OPCAB led to small increases in MMP-2 levels, and this effect was statistically significant after surgical intervention. Data points are means \pm standard deviation $(n=20)$. Bottom, Representative zymograms of patients with $C A B G(C)$ and OPCAB (D): ST1 and ST2 standards. 
TABLE 2. Clinical characteristics of study groups

\begin{tabular}{lccc}
\hline & CABG $(\mathbf{n}=\mathbf{2 0})$ & OPCAB $(\mathbf{n}=\mathbf{2 0})$ & $\boldsymbol{P}$ value \\
\hline Mean age (y) & $61.5 \pm 8.32$ & $62.6 \pm 10.91$ & NS \\
Male/female sex & $19 / 1$ & $16 / 4$ & NS \\
Hypertension, $\mathrm{n}$ & $20(100 \%)$ & $15(75 \%)$ & $\mathrm{NS}$ \\
Hypercholesterolemia, $\mathrm{n}$ & $11(55 \%)$ & $10(50 \%)$ & $\mathrm{NS}$ \\
Diabetes mellitus, $\mathrm{n}$ & $4(20 \%)$ & $4(20 \%)$ & $\mathrm{NS}$ \\
History of smoking, $\mathrm{n}$ & $7(35 \%)$ & $10(50 \%)$ & $\mathrm{NS}$ \\
Obesity (BMI $>30), \mathrm{n}$ & $12(60 \%)$ & $15(75 \%)$ & $\mathrm{NS}$ \\
NYHA class & $1.25 \pm 0.44$ & $1.55 \pm 0.69$ & $\mathrm{NS}$ \\
CCS grade & $2.55 \pm 011$ & $2.3 \pm 0.57$ & $\mathrm{NS}$ \\
LVEF (\%) & $45.40 \pm 9.8$ & $45.25 \pm 8.9$ & $\mathrm{NS}$ \\
EuroSCORE & $2.85 \pm 1.55$ & $3.85 \pm 2.3$ & $\mathrm{NS}$ \\
No. of grafts & $2.75 \pm 0.55$ & $2.10 \pm 0.85$ & .01 \\
\hline
\end{tabular}

$C A B G$, Coronary artery bypass grafting; $O P C A B$, off-pump coronary artery bypass; $N S$, not significant; $B M I$, body mass index; $N Y H A$, New York Heart Association; $C C S$, Canadian Cardiovascular Society; $L V E F$, left ventricular ejection fraction.

\section{Plasma TIMP-1 and TIMP-2}

Because the activity of MMP-9 is inhibited by endogenous TIMP-1 and TIMP-2, the time course of plasma concentrations of these inhibitors was also measured (Figure 3). Concentrations of TIMP-1 were maximally increased at time point $\mathrm{F}$ by approximately 2.7 -fold and approximately 1.7 fold for the CABG and OPCAB groups, respectively.
In contrast, concentrations of TIMP-2 were maximally increased at time point D by approximately 3.8-fold for the OP$\mathrm{CAB}$ group and approximately 5.9-fold for the CABG group.

Because both TIMP-1 and TIMP-2 bind to gelatinases with a stechiometric ratio of 1:1 with similar affinity, we calculated the cumulative concentration of TIMPs in plasma at every time point. The maximal increase in total TIMP-1 and TIMP-2 concentrations in plasma at the time of maximal MMP-9 and MMP-2 release was only approximately 2.1fold higher than the basic level for the OPCAB group and approximately 2.8 -fold higher for the CABG group. Thus the MMP-9 increase (700- to 900-fold) during the CABG procedure could not be counterbalanced by similar increase of TIMP concentrations.

\section{Plasma MPO}

A specific marker of neutrophil activation, MPO, was measured at point D, corresponding to the maximal MMP-9 release. The MPO levels were significantly higher in the $\mathrm{CABG}$ group than in the OPCAB group (Figure $4, A$ ). Moreover, in the $\mathrm{CABG}$ group there was a significant correlation $\left(r^{2}=0.82, P<.005\right)$ between MPO and MMP-9 levels at the time of the maximal release of MMP-9 (Figure 4, B). No significant correlation was observed in the OPCAB group.

MMP-9
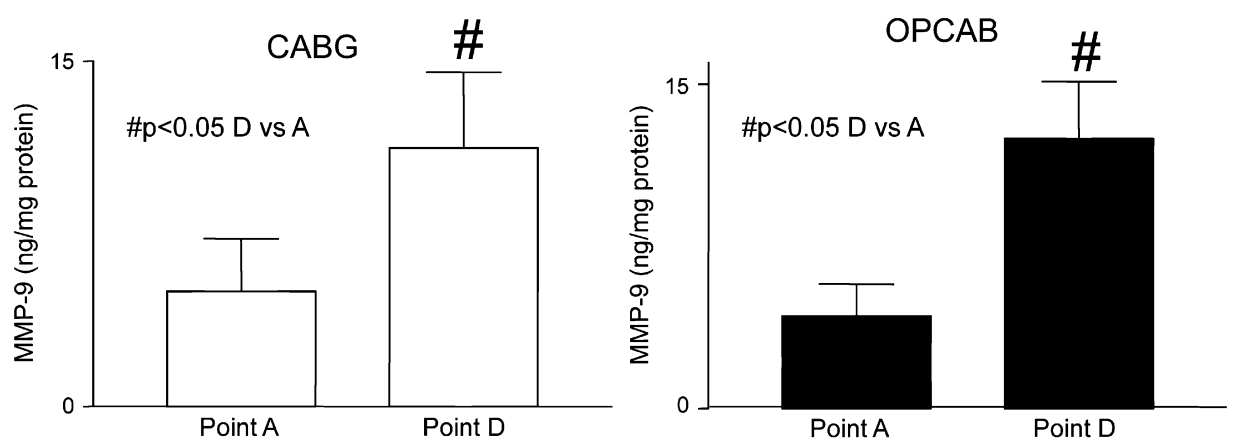

A

MMP-2

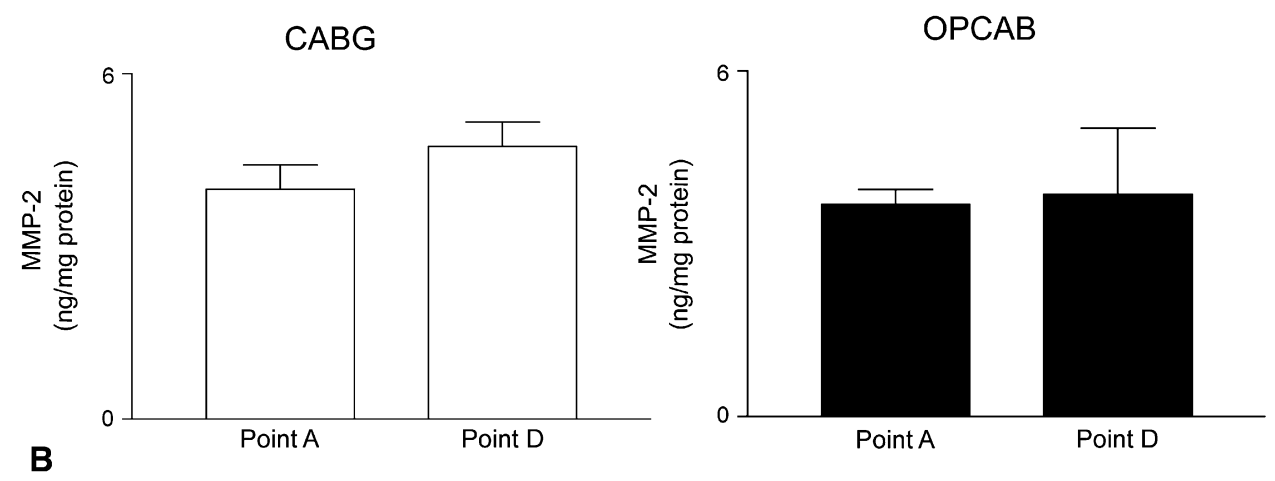

FIGURE 2. Myocardial gelatinase levels during coronary artery bypass grafting $(C A B G)$ and off-pump coronary artery bypass $(O P C A B)$. The levels of matrix metalloproteinase (MMP) 9 (A), but not MMP-2 (B), were increased during both types of operation. Bar graphs show mean values \pm standard deviation $(\mathrm{n}=20)$. 

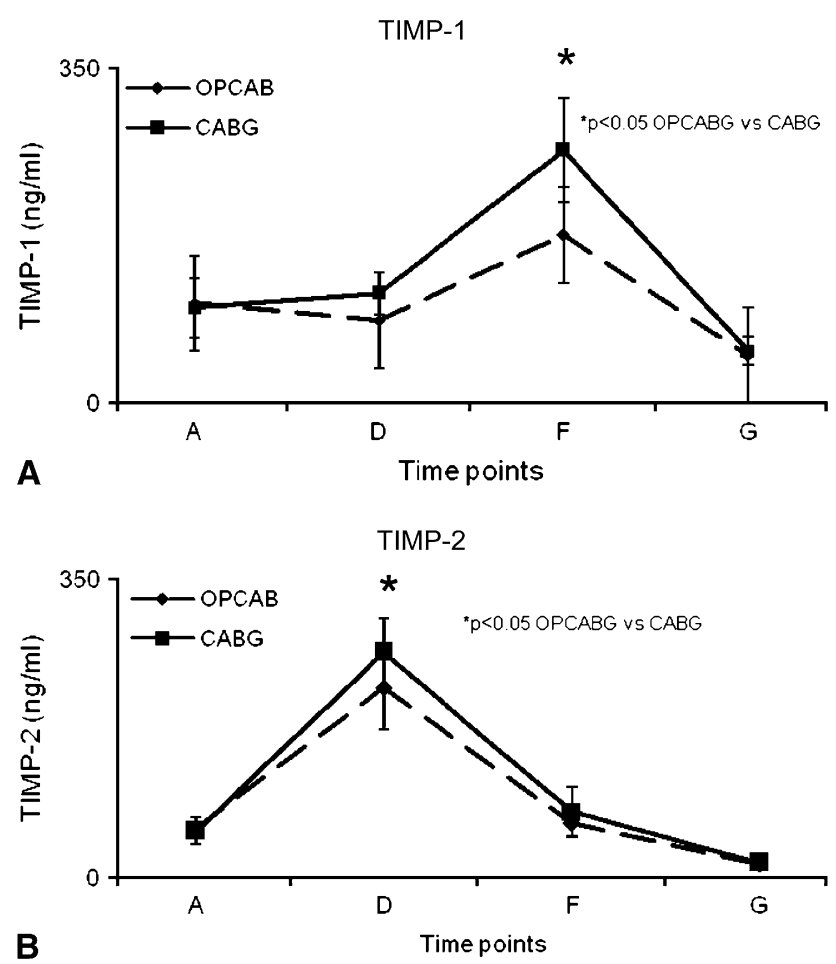

FIGURE 3. Changes in plasma tissue inhibitor of metalloproteinase (TIMP) 1 (A) and TIMP-2 (B) concentrations during coronary artery bypass grafting $(C A B G)$ and off-pump coronary artery bypass $(O P C A B)$. Data points are means \pm standard deviation $(\mathrm{n}=20)$.

\section{DISCUSSION}

Several authors have reported an increase in MMP levels in plasma and heart tissue during cardiac surgery $9,11,12,14,16$ or after experimentally induced heart ischemia in animal models. ${ }^{17,18}$ Some of these reports evidenced increased MMP/TIMP ratios that led to increased inflammatory responses unopposed by inhibitor actions of MMPs. ${ }^{9,12,16,17}$ Interestingly, most of the studies that focused on the measurement of MMPs during the ECC procedure assumed (without any experimental confirmation) that observed changes in MMP activity were caused by ECC but not by the surgical procedure itself. For example, Lin and colleagues ${ }^{16}$ measured MMP-9 plasma concentrations using enzyme-linked immunosorbent assays in 16 patients undergoing $\mathrm{CABG}$ and 5 patients undergoing OPCAB. They observed no change in MMP-9 concentrations during the OPCAB procedure. The highest MMP-9 increase (approximately 2.5 -fold) was observed 4 hours after the beginning of CABG. In contrast, Lalu and associates ${ }^{12}$ reported an almost 100-fold increase of MMP-9 activity directly after ECC discontinuation compared with the baseline concentration measured in samples collected shortly after initiation of ECC but before ischemia. The current work has been designed to address a number of outstanding questions related to interactions between gelatinases (MMP-2 and MMP-9), ECC, and cardiac surgery.

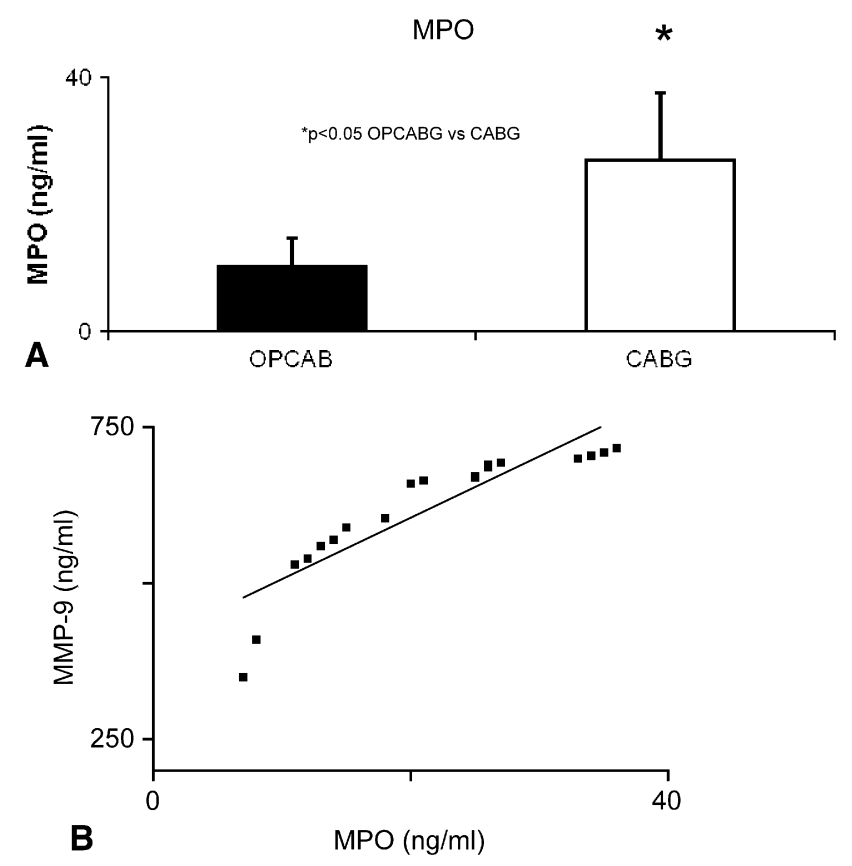

FIGURE 4. A, Comparison of myeloperoxidase $(M P O)$ concentrations in plasma in the coronary artery bypass grafting $(C A B G)$ and off-pump coronary artery bypass $(O P C A B)$ groups at the point of maximal matrix metalloproteinase $(M M P) 9$ release. Data points are means \pm standard deviation $(\mathrm{n}=20)$. B, Correlation plot between MPO and MMP-9 concentrations in plasma in the CABG group at the point of maximal MMP-9 release.

First, are both gelatinases increased during $\mathrm{CABG}$ and OPCAB? This is a very pertinent problem because the 2 enzymes, although belonging to the same family of MMPs, have different biologic profiles in their interactions with the vasculature and platelets. ${ }^{19}$ Second, is the presence of ECC responsible for the systemic release of gelatinases, or are they released in response to surgical manipulations? Third, can MMP upregulation be effectively opposed by the concomitant increase in TIMPs? Finally, what is the likely cellular source of MMPs released during cardiac surgery?

To address these questions, we compared tissue and plasma levels of MMP-2 and MMP-9 at different time points of CABG and OPCAB. Moreover, we measured plasma concentrations of TIMP-1 and TIMP-2 to assess the functional importance of observed changes in the activity of MMPs. Finally, we assayed MPO levels to evaluate whether neutrophil activation with associated release of gelatinase granules could be held accountable for the release of MMP-2, MMP-9, or both.

The most striking finding obtained in this study was the response of MMP-9 to ECC. In less than 2 hours after initiation of EEC, plasma levels of MMP-9 were increased by 700- to 900-fold. Furthermore, the rapid clearance (within 6 hours) of enzyme from the circulation coincided with the cessation of ECC. In contrast, in patients undergoing OP$\mathrm{CAB}$, the levels of MMP-9 remained unchanged during the operation, indicating that the systemic MMP-9 release 
is clearly correlated with ECC but not with the surgical procedure itself. Interestingly, MMP-2 levels do not appear to increase in a significant way during ECC, and its levels are only moderately increased after discontinuation of ECC in the early postoperative period.

What might be the biologic and clinical significance of this dramatic increase of MMP-9? For a short period $(<6$ hours) after its release, the biologic effects of MMP-9 are likely to be unopposed because the concomitant stimulation of TIMPs (several fold increase) is not strong enough to counteract a several-hundred-fold increase in MMP-9 levels. However, the biologic consequences of even a short-lasting increment in MMP-9 levels can be of importance because the enzyme has been shown to acutely inhibit platelet aggregation and play a central role in relaxin-mediated vasorelaxation. $^{20-22}$ There is also evidence that a short-term increase in MMP-9 levels could have important repercussion for cardiac ischemia. Recently, Kelly and colleagues ${ }^{23}$ showed that maximal MMP-9 increase in the first 20 hours of myocardial infarction had an independent predictive value for lower LVEF during admission and for greater change in left ventricular end-diastolic volume between admission and follow-up. These findings seem to confirm the previous results of Lalu and colleagues, ${ }^{12}$ who showed negative correlation between myocardial MMP-9 and MMP-2 activity and left ventricular mechanical function. However, the effect of increased MMP-9 concentrations during CABG on late postoperative cardiac function requires further investigation.

What about long-lasting effects of systemic increase of MMP-9 levels in other organs? ECC has been shown to generate a myriad of neuropsychologic and neuropsychiatric deviations that might last years after the exposure of patients to ECC. ${ }^{24,25}$ This impairment is accompanied by the release of neurobiochemical markers of brain damage (protein S-100B and neuron-specific enolase). ${ }^{26}$ Many different mechanisms underlying the phenomenon were proposed, including microembolization and inadequate cerebral flow. ${ }^{24,27}$ There is substantial evidence linking blood-brain barrier failure during cerebral ischemia to MMPs. ${ }^{28-32}$ We have found that myocardial MMP-9 and MMP-2 levels increased postoperatively to a similar extent during both $\mathrm{CABG}$ and OP$\mathrm{CAB}$, indicating that this effect is caused predominantly by intraoperative trauma/ischemia and might not be caused by ECC. Interestingly, Cheung and coworkers ${ }^{18}$ have shown, in an ex vivo model of an isolated working rat heart, that ischemia and reperfusion lead to release of MMP-2 from cardiac muscle and that MMP-2 contributes to cardiac mechanical dysfunction, an effect dependent on degradation of the myosin light chain. ${ }^{33}$ Whether a cardiac surgery-induced increase in myocardial gelatinases affects myocardial performance remains to be demonstrated.

The synthesis and secretion of MMPs by several cells can be stimulated by different growth factors and cytokines, including IL- $1 \alpha$ and IL- $1 \beta$, tumor necrosis factor $\alpha$, transform- ing growth factor $\alpha$, basic fibroblast growth factor, and others. $^{34,35}$ Interestingly, some of these mediators can rapidly cause an even 50-fold increase in MMP mRNA levels. However, the MMP protein synthesis process is a longerlasting one, and therefore increased MMP release is not observed until a few hours after stimulation. In our study a significant increase in MMP-9 activity in plasma was observed at point $\mathrm{C}$ and a maximal increase was seen at point D (approximately 156 and 193 min after the beginning of the procedure or approximately 79 and 116 minutes after ECC initiation, respectively; Table 1). In contrast to the de novo protein synthesis, the release of MMP-9 by means of degranulation of gelatinase granules is a fast event in neutrophils and occurs within less than 1 hour when these cells are stimulated with chemotactic factors, including the major neutrophil chemokine IL-8. This again contrasts with the de novo synthesis of gelatinase B by monocytes, which is at least 10 fold slower. ${ }^{36}$ A specific marker of neutrophil degranulation, MPO, was measured in plasma samples to ascertain whether leukocyte degranulation took place during the time of MMP9 release. As expected, MPO levels were significantly higher in the CABG group than in the OPCAB group at the point of maximal MMP-9 release. Moreover, MPO levels closely correlated with MMP-9 levels $\left(r^{2}=0.82, P<0.005\right)$. In contrast, no significant correlation was observed in the OPCAB group. Therefore we propose that MMP-9 was released from leukocyte gelatinase granules as a result of ECC-induced cellular injury. However, we cannot definitely exclude the possibility that MMP-9 increases were caused not by ECC but by ischemic cardiac arrest.

In conclusion, we have found that MMP-9 is differentially released to the systemic circulation during $\mathrm{CABG}$ and OPCAB surgery. However, surgical manipulations of myocardium result in local upregulation of this enzyme. Therefore we propose that the release of MMP-9 might contribute to ECC-induced inflammatory reactions.

Finally, despite very similar characteristic of both studied groups, it needs to be acknowledged that for ethical reasons the study was not randomized, and this potentially could influence its results.

\section{References}

1. Biondi-Zoccai GG, Abbate A, Agostoni P, Parisi Q, Turri M, Anselmi M, et al. Stenting versus surgical bypass grafting for coronary artery disease: systematic overview and meta-analysis of randomized trials. Ital Heart J. 2003;4: 271-80

2. Kestin AS, Valeri CR, Khuri SF, Loscalzo J, Ellis PA, MacGregor H, et al. The platelet function defect of cardiopulmonary bypass. Blood. 1993;82:107-17.

3. Rinder CS, Gaal D, Student LA, Smith BR. Platelet-leukocyte activation and modulation of adhesion receptors in pediatric patients with congenital heart disease undergoing cardiopulmonary bypass. J Thorac Cardiovasc Surg. 1994; 107:280-8.

4. Goldstein DJ, Beauford RB, Luk B, Karanam R, Prendergast T, Sardari F, et al. Multivessel off-pump revascularization in patients with severe left ventricular dysfunction. Eur J Cardiothorac Surg. 2003;24:72-80.

5. Medina C, Radomski M. Role of matrix metalloproteinases in intestinal inflammation. J Pharmacol Exp Ther. 2006;318:933-8. 
6. Coker ML, Doscher MA, Thomas CV, Galis ZS, Spinale FG. Matrix metalloproteinase synthesis and expression in isolated LV myocyte preparations. Am J Physiol Heart Circ Physiol. 1999;277:H777-87.

7. Nataatmadja M, West J, West M. Overexpression of transforming growth factorbeta is associated with increased hyaluronan content and impairment of repair in Marfan syndrome aortic aneurysm. Circulation. 2006;114(suppl):I371-7.

8. Montero I, Orbe J, Varo N, Beloqui O, Monreal JI, Rodriguez JA, et al. C-reactive protein induces matrix metalloproteinase- 1 and -10 in human endothelial cells: implications for clinical and subclinical atherosclerosis. J Am Coll Cardiol. 2006;47:1369-78.

9. Galley HF, Macaulay GD, Webster NR. Matrix metalloproteinase-9, tissue inhibitor of metalloproteinase- 1 and tumour necrosis factor a release during cardiopulmonary bypass. Anesthesia. 2002;57:659-62.

10. Wan S, LeClers JL, Vincent JL. Inflammatory response to cardiopulmonary bypass: mechanisms involved and possible therapeutic strategies. Chest. 1997; 112:676-92.

11. Joffs C, Gunasinghe HR, Multani MM, Dorman BH, Kratz JM, Crumbley AJ 3rd, et al. Cardiopulmonary bypass induces the synthesis and release of matrix metalloproteinases. Ann Thorac Surg. 2001;71:1518-23.

12. Lalu MM, Pasini E, Schulze CJ, Ferrari-Vivaldi M, Ferrari-Vivaldi G, Bachetti T, et al. Ischaemia-reperfusion injury activates matrix metalloproteinases in the human heart. Eur Heart J. 2005;26:27-35.

13. Sawicki G, Salas E, Murat J, Miszta-Lane H, Radomski MW. Release of gelatinase A during platelet activation mediates aggregation. Nature. 1997;386:616-9.

14. Mayers I, Hurst T, Puttagunta L, Radomski A, Mycyk T, Sawicki G, et al. Cardiac surgery increases the activity of matrix metalloproteinases and nitric oxide synthase in human hearts. J Thorac Cardiovasc Surg. 2001;122:746-52.

15. Radomski A, Jurasz P, Sanders EJ, Overall CM, Bigg HF, Edwards DR, et al. Identification, regulation and role of tissue inhibitor of metalloproteinases-4 (TIMP-4) in human platelets. Br J Pharmacol. 2002;137:1330-8.

16. Lin TC, Li CY, Tsai CS, Ku CH, Wu CT, Wong CS, et al. Neutrophil-mediated secretion and activation of matrix metalloproteinase- 9 during cardiac surgery with cardiopulmonary bypass. Anesth Analg. 2005;100:1554-60.

17. Schulze CJ, Wang W, Suarez-Pinzon WL, Sawicka J, Sawicki G, Schulz R. Imbalance between tissue inhibitor of metalloproteinase-4 and matrix metalloproteinases during acute myocardial ischemia-reperfusion injury. Circulation. 2003; 107:2487-92.

18. Cheung PY, Sawicki G, Wozniak M, Wang W, Radomski MW, Schulz R. Matrix metalloproteinase-2 contributes to ischemia-reperfusion injury in the heart. Circulation. 2000;101:1833-9.

19. Santos-Martinez MJ, Medina C, Jurasz P, Radomski MW. Role of metalloproteinases in platelet function. Thromb Res. 2008;121:535-42.

20. Jeyabalan A, Novak J, Doty KD, Matthews J, Fisher MC, Kerchner LJ, et al. Vascular matrix metalloproteinase- 9 mediates the inhibition of myogenic reactivity in small arteries isolated from rats after short-term administration of relaxin. Endocrinology. 2007;148:189-97.

21. Fernandez-Patron C, Martinez-Cuesta MA, Salas E, Sawicki G, Wozniak M, Radomski MW, et al. Differential regulation of platelet aggregation by matrix metalloproteinases-9 and -2. Thromb Haemost. 1999;82:1730-5.
22. Santos-Martinez MJ, Medina C, Jurasz P, Radomski MW. Role of metalloproteinases in platelet function. Thromb Res. 2008;121:535-42.

23. Kelly D, Cockerill G, Ng LL, Thompson M, Khan S, Samani NJ, et al. Plasma matrix metalloproteinase- 9 and left ventricular remodelling after acute myocardial infarction in man: a prospective cohort study. Eur Heart J. 2007;28:711-8.

24. Roach GW, Kanchuger M, Mangano CM, Newman M, Nussmeier N, Wolman R, et al. Adverse cerebral outcomes after coronary bypass surgery. $N$ Engl J Med. 1996;335:1857-63.

25. Gill R, Murkin JM. Neuropsychologic dysfunction after cardiac surgery: what is the problem? J Cardiothorac Vasc Anesth. 1996;10:91-8.

26. Herrmann M, Ebert AD, Galazky I, Wunderlich MT, Kunz WS, Huth C. Neurobehavioral outcome prediction after cardiac surgery: role of neurobiochemical markers of damage to neuronal and glial brain tissue. Stroke. 2000;31: 645-50.

27. Clark RE, Brillman J, Davis DA, Lovell MR, Price TRP, Magovern GJ. Microemboli during coronary artery bypass grafting: genesis and effect on outcome. $J$ Thorac Cardiovasc Surg. 1995;109:249-58.

28. Rosenberg GA, Estrada EY, Dencoff JE. Matrix metalloproteinases and TIMPs are associated with blood-brain barrier opening after reperfusion in rat brain. Stroke. 1998;29:2189-95.

29. Krizanac-Bengez L, Hossain M, Fazio V, Mayberg M, Janigro D. Loss of flow induces leukocyte-mediated MMP/TIMP imbalance in dynamic in vitro bloodbrain barrier model: role of pro-inflammatory cytokines. Am J Physiol Cell Physiol. 2006;291:C740-9.

30. Romanic AM, White RF, Arleth AJ, Ohlstein EH, Barone FC. Matrix metalloproteinase expression increases after cerebral focal ischemia in rats: inhibition of matrix metalloproteinase-9 reduces infarct size. Stroke. 1998;29:1020-30.

31. Yang Y, Estrada EY, Thompson JF, Liu W, Rosenberg GA. Matrix metalloproteinase-mediated disruption of tight junction proteins in cerebral vessels is reversed by synthetic matrix metalloproteinase inhibitor in focal ischemia in rat. J Cereb Blood Flow Metab. 2007;27:697-709.

32. Gidday JM, Gasche YG, Copin JC, Shah AR, Perez RS, Shapiro SD, et al. Leukocyte-derived matrix metalloproteinase- 9 mediates blood-brain barrier breakdown and is proinflammatory after transient focal cerebral ischemia. Am $J$ Physiol Heart Circ Physiol. 2005;289:H558-68.

33. Sawicki G, Leon H, Sawicka J, Sariahmetoglu M, Schulze CJ, Scott PG, et al. Degradation of myosin light chain in isolated rat hearts subjected to ischemia-reperfusion injury: a new intracellular target for Matrix Metalloproteinase-2. Circulation. 2005; 112:544-52.

34. Birkedal-Hansen H, Moore WG, Bodden MK, Windsor LJ, Birkedal-Hansen B, DeCarlo A, et al. Matrix metalloproteinases: a review. Crit Rev Oral Biol Med. 1993;4:197-250.

35. Fabunmi RP, Baker AH, Murray EJ, Booth RF, Newby AC. Divergent regulation by growth factors and cytokines of $95 \mathrm{kDa}$ and $72 \mathrm{kDa}$ gelatinases and tissue inhibitors or metalloproteinases-1, -2 , and -3 in rabbit aortic smooth muscle cells. Biochem J. 1996;315:335-42.

36. Opdenakker G, Van den Steen PE, Dubois B, Nelissen I, Van Coillie E, Masure S, et al. Gelatinase B functions as regulator and effector in leukocyte biology. J Leukoc Biol. 2001;69:851-9. 